$$
\zeta
$$




\section{Sobre el concepto de valor intrínseco en ética ambiental}

\section{Introducción}

El objetivo de este trabajo es hacer una revisión de las principales teorías que se han propuesto en ética ambiental en torno a la noción de valor intrínseco. Para esto, dilucidaré qué se entiende por valor intrínseco, para después remarcar la importancia que tiene este concepto dentro de la reflexión sobre el medio ambiente. Por último, perfilaré las principales teorías de corte biocentrista dentro de la ética ambiental que han tratado la noción de valor intrínseco como eje central.

\section{Medio Ambienteः sus exponentes}

No cabe duda de que la máxima de Aldo Leopold, "algo es correcto cuando tiende a preservar la integridad, estabilidad y belleza de la comunidad biótica; es incorrecto cuando tiende a lo contrario" ${ }^{1}$, es considerada como el evangelio de la filosofía medioambiental y ha permeado sus reflexiones durante el siglo pasado. En la frase anterior, el criterio moral estriba en que las acciones humanas eviten la destrucción de ecosistemas sin más, es decir, en función de sí mismos y no de las utilidades económicas que esto genere. Ésta ha sido la interpretación de algunos como Callicott; otros, como Bryan Norton, insisten en que Leopold tenía en mente otra cosa, algo más parecido a una correcta administración de los recursos que permitiera solucionar problemas prácticos concretos ${ }^{2}$.

1 Aldo Leopold, La ética de la tierra, en Valdés, Margarita M. (comp.), Naturaleza y valor, una aproximación a la ética ambiental, p. 43.

2 Cfr., Bryan Norton, ¿Por qué no soy no-antropocentrista?, en Kwiatkowska, Teresa et al., Jorge Issa (comps.), Los caminos de la ética ambiental, Vol II, CONACYT, México, 1998, p. 131. 
Sea cual sea la interpretación de este pasaje, sigue estando presente el problema fundamental de si debemos cuidar el medio ambiente por los servicios ecológicos que nos suministra, o si, por el contrario, debemos protegerlo porque tiene, como algunos teóricos lo llaman, valor intrínseco. Pues, ¿qué motivo ha tenido el ser humano para desviar la mirada de sí mismo hacia una realidad que, si bien lo determina hasta cierto grado, considerada en sí misma (ontológicamente) es tan distinta de él?

La preocupación acerca de si tenemos deberes en relación con el medio natural es reciente. No figura en los antiguos, para quienes el cosmos era un conjunto ordenado e infinito, ni entre los modernos, que concebían la naturaleza como una máquina susceptible de ser dominada. Un pionero en la reflexión de este tipo de cuestiones fue el filósofo alemán Hans Jonas, quien hizo notar que el ser humano se enfrentaba a un nuevo tipo de problemas derivados de su gran capacidad para alterar el mundo natural con la tecnología, los cuales ponían en peligro la existencia misma de sus capacidades morales. Según Jonas, la ética tradicional es incapaz de responder a los problemas planteados por la tecnología, pues su ámbito ha sido totalmente rebasado por las capacidades que ésta ha brindado a los seres humanos. De acuerdo con él, son cuatro características suyas las que la hacen obsoleta. La primera de ellas se refiere a la neutralidad de las acciones humanas respecto de la biósfera, pues éstas, anteriormente impotentes para cambiarla, no se planteaban la relevancia del mundo natural en sus reflexiones. Una segunda característica es que "lo que tenía relevancia ética era el trato directo del hombre con el hombre" ${ }^{\prime 3}$. De aquí que, según Jonas, fuera esencialmente antropocéntrica. Otra de sus características se refiere a la concepción de la esencia humana como inmodificable, es decir, a la creencia de que el ser humano, entendido como bomo sapiens sapiens, tenía una estructura bien definida y difícilmente modificable. Aún no se vislumbraban las posibilidades que, por ejemplo, la genética alumbraría en el futuro. Por último, la ética tradicional no paraba mientes en el alcance de las acciones porque éstas solían restringirse al ámbito del trato inmediato con otros seres humanos. De aquí que, según Jonas, un nuevo tipo de ética debiera surgir.

3 Cfr. Jonas, Hans, El principio de responsabilidad. Ensayo de una ética para la civilización tecnológica, Ed. Herder, España, 1993, pp. 29-31. 
No obstante, con Jonas vemos que la principal razón por la que debemos cuidar el medio ambiente es para nuestro propio bienestar, para asegurar nuestra supervivencia. En este sentido, el criterio utilizado para regular nuestras acciones frente al medio ambiente somos nosotros mismos, motivo por el que se ha calificado a esta actitud como antropocentrista. Sin embargo, muchos autores insertos en la ética ambiental han optado por otro camino, denominándose a sí mismos no antropocentristas, por considerar que la reflexión de nuestra conducta en relación con el medio ambiente natural no debe basarse en el cálculo de utilidades materiales, sino en el valor intrínseco que, según ellos, poseen los seres vivos.

Se dice que algo merece consideración moral porque es valioso, es decir, porque tiene cualidades que hacen preferible su existencia a su no existencia. Un ejemplo paradigmático de esto es la dignidad humana, formulada de manera genial por Immanuel Kant, para quien todo ser humano es un fin en sí mismo, dada su naturaleza racional. En este sentido, según Kant nadie debe ser tratado como medio por ningún otro ser humano, ya que esto anularía la aspiración racionalista a una ley universal de conducta. En lo tocante a las teorías de ética ambiental, se dice que una cosa posee valor intrínseco porque tiene ciertas cualidades que la hacen acreedora a nuestra consideración.

\section{Ética ambiental: su razón de ser}

El término ética ambiental surge por primera vez en 1973, a raíz de un texto presentado por Richard Routley en el XV Congreso Mundial de Filosofía, al cual tituló: Is there a need for a new, an environmental, ethic? Este artículo es de especial importancia, pues en él Routley formula una crítica hacia el chauvinismo humano, entendido éste como la presunción de que la especie humana es superior a las demás y que por este hecho tiene derechos sobre ellas. Esta disciplina cuestiona nuestras actitudes con respecto a los seres vivos no humanos y los ecosistemas, planteándose la posibilidad de que éstos tengan valor intrínseco independiente de cualquier uso que se les pueda dar, además de ofrecer razones por las cuales deberíamos otorgarles consideración moral.

Se ha dicho que la ética ambiental es una forma de extensión de la ética, con la cual se busca ampliar el ámbito de la moralidad 
fuera de las categorías tradicionales. Si bien la conocida propuesta de Peter Singer ha contribuido a este propósito ${ }^{4}$, al utilizar criterios utilitaristas basados en el binomio dolor-placer, sigue limitando el valor intrínseco a experiencias subjetivas y, en todo caso, a estados conscientes. Las posturas de la ética ambiental tratan de ir más allá del criterio de sensibilidad, y justificar principios de conducta con base en categorías meramente biológicas. Éstas suelen clasificarse en dos tipos: biocentrismo y ecocentrismo ${ }^{5}$. Según el primero, los animales no humanos y las plantas, en tanto individuos, deben ser objetos de consideración moral, ya sea porque poseen "valía inherente" o porque son "sujetos de una vida".

El biocentrismo defiende que la existencia de intereses particulares, presentes en cada individuo, es razón suficiente para tener consideración moral hacia ellos en función de sí mismos y no de otra cosa. Esta postura aboga más por los seres individuales que por los colectivos, lo que ha generado un amplio debate con la otra postura, la denominada ecocéntrica. De acuerdo con ésta, es necesario ampliar el círculo de nuestra moralidad para incluir a las especies y a los ecosistemas. Según sostiene, la preservación y la conservación del medio ambiente únicamente pueden realizarse si se admite que no sólo los individuos son los únicos merecedores de consideración moral, sino también otras entidades como los ecosistemas. Además, los filósofos insertos en esta corriente suelen hacer uso de la teoría evolucionista para justificar el aumento del alcance de nuestra moralidad, lo que implica problemas no menos difíciles que el relativo al valor intrínseco, a saber, aquel que se refiere a la falacia naturalista. Las posturas biocéntricas defienden que los seres vivos son valiosos en un nivel individual e intentan descubrir un criterio por el que puedan ser dignas de consideración moral.

4 No se hablará mucho de esta teoría conocida como zoocentrismo, pues si bien es importante por ser una buena crítica al punto de vista antropocentrista, su marco teórico se aleja mucho del propósito general de esta investigación, al reducir el ámbito de lo moral al placer y el dolor propios de los animales.

5 Kwiatkowska, Teresa et al., Jorge Issa (comps.), Los caminos de la ética ambiental, CONACYT, México, 1998, pp. 79 y 263.

6 Uno de los autores más representativos de este paradigma es Paul Taylor, quien fundamenta un principio moral del respeto basándose en los intereses y el bienestar de los individuos vivientes. Cfr. Paul Taylor, La ética del respeto a la naturaleza, UNAM, México, 2005. 
Tres conceptos son importantes dentro de este tipo de postura, a saber: el bien propio, el valor intrínseco y los intereses. Kenneth Goodpaster y Paul Taylor son los representantes más destacados de esta postura; sobre sus teorías se han asentado los principios morales más importantes del biocentrismo. Goodpaster sostiene, por un lado, la tesis de que es necesario otorgar consideración moral a los seres vivos no humanos en función de su vida. Para él, el criterio de sensibilidad propuesto por algunos eticistas no es suficiente para la consideración moral, pues si bien es cierto que con él se amplía el círculo de lo moral, éste sólo capta una parte de lo que significa estar vivo. Según Goodpaster: "La sensibilidad es una característica que favorece la adaptación de los organismos vivos ya que les otorga una mejor capacidad para anticipar, y de este modo evitar, amenazas a su vida [... ] las capacidades de sufrir y disfrutar se derivan de algo más importante" 7 . En el pasaje citado nos parece decir que la vida es considerada como un criterio más razonable que la sensibilidad, pues ésta surge en función de su supervivencia. Así, ésta sería sólo uno de los tantos modos que los seres vivos desarrollan para proteger algo más valioso: la vida.

Goodpaster da un paso adelante y critica a aquellos que niegan que los seres vivos no sensibles carezcan de intereses, por encontrarse éstos en las experiencias conscientes. Según él,"las capacidades psicológicas o hedonistas parecen innecesariamente complejas cuando se trata de localizar las condiciones mínimas para que algo merezca ser valorado por sí mismo" ${ }^{8}$. Estas reflexiones lo llevan a establecer lo que él llama el "principio de vida" y a negar la ética hedonista, que predispone a los seres humanos a anteponer la sensibilidad a la vida.

\section{La propuesta de Paul Taylor}

En un segundo momento, encontramos a Paul Taylor y su caracterización de los seres vivos como "centros teleológicos de vida". De acuerdo con él, el fin último de una ética del medio ambiente consiste en lograr una actitud de respeto hacia la naturaleza, que vea el bienestar de los seres vivos como un fin en sí mismo. Ésta sólo es posible si los seres humanos están imbuidos en un sistema de

7 Goodpaster, Kenneth, Sobre lo que merece consideración moral. Ibidem p. 157.

8 Ibidem p. 161. 
creencias que les permita interpretar adecuadamente el fenómeno de la vida. Taylor parece recalcar mucho este punto, y sienta cuatro requisitos para tener una visión adecuada de la vida: 1) concebir a los humanos como integrantes de la biocomunidad, 2) concebir los ecosistemas como una red de elementos interconectados (de los cuales el ser humano es parte), 3) concebir a los organismos como centros teleológicos de vida, y 4) aceptar que los seres humanos no son superiores a ninguna especie ${ }^{9}$. Según Taylor, los tres primeros requisitos son una mera preparación para el cuarto, que una vez realizado podrá cambiar la actitud de los seres humanos en relación con la naturaleza. De este modo, cree que el rechazo de la superioridad humana frente a la naturaleza es el momento más importante en la consolidación de una ética ambiental. A partir de este punto, Taylor critica a la tradición occidental y su supuesto de que los seres humanos son más valiosos porque poseen características consideradas superiores, tales como la racionalidad o la capacidad estética. Taylor arguye que esta afirmación se basa en los juicios de mérito, los cuales otorgan más valor a un ser en función de sus capacidades. Sin embargo, los critica diciendo que cada ser vivo posee habilidades sui géneris, no comparables las unas con las otras, y que éstas les sirven de forma particular para realizar su bien propio y lograr un estado de bienestar.

La superioridad humana tampoco se puede establecer, según Taylor, con base en su valor inherente, puesto que cuando "dirigimos nuestra atención a la vida individual de las plantas y los animales, éstos aparecen compartiendo con nosotros la característica de ser un centro teleológico de vida que se esfuerza por lograr su propio bien a su modo propio y singular" ${ }^{10}$. Así, vemos que su aproximación al concepto de valor intrínseco se caracteriza por su concepto de valor inherente, que está ligado a la finalidad que éstos se esfuerzan en completar.

Taylor cree encontrar una relación de interdependencia entre lo que la gente conoce y sus conductas. En este sentido, se suscribe en lo que se conoce como la tesis psico-conductual, según la cual la gente que cree en el valor intrínseco de los seres naturales tiende a actuar de forma más ambiental que la que no. Cree que

9 Cfr. Taylor, Paul, La ética del respeto a la naturaleza en Teresa et al., Jorge Issa (comps.), Los caminos de la ética ambiental, CONACYT, México, 1998, p. 273.

10 Ibidem p. 285. 
conociendo las características de los seres vivos y sus relaciones con su ecosistema es posible entender su modo de existencia tal cual es; confía en que nuestras actitudes hacia el mundo natural cambiarán cuando nos hagamos conscientes de un concepto de los seres vivos científicamente informado. Según él,"una vez que nos oponemos a la pretensión de que los humanos son superiores a las demás cosas vivas, estamos listos para adoptar la actitud de respeto" ${ }^{11}$ No para mientes en que el conocimiento descriptivo de un objeto no implica normas de conducta hacia él. En este sentido, parece caer en una especie de falacia naturalista.

\section{Conclusión}

Las teorías de Taylor y Goodpaster se conocen como igualitarismo biótico y biocentrismo moderado, respectivamente. Sin embargo, la visión biocentrista en ética ambiental presenta algunas dificultades. Una de ellas se refiere a la dimensión individualista del ámbito de la consideración moral. ¿'Todos los organismos merecen que se respete su existencia, aun cuando algunos de ellos sean dañinos para otros organismos, por ejemplo, la bacteria Salmonella, y sean responsables de la muerte de otros seres vivos? Siguiendo la teoría de Taylor, la respuesta debería ser afirmativa, lo cual es, además, inconsistente con las necesidades metabólicas de los seres vivientes.

En efecto, todo ser viviente se alimenta de otros seres vivos para sobrevivir. Si aceptáramos la teoría de los biocentristas, estaríamos negando de cierto modo la vida. Otra dificultad que presenta esta corriente es que no puede responder si sería más deseable salvar a un miembro de una especie en peligro de extinción que a muchos de ellos que no lo están. Con todo, estas teorías han sido relegadas en el presente por lo que se conoce como pragmatismo ambiental. Qué tanto nos puedan decir en la actualidad es una cuestión que ha perdido importancia.

11 Ibidem p. 286. 